\title{
Modeling of High-Temperature Electron-Ion Interaction in Metals
}

\author{
E. S. Filippov ${ }^{1}$ \\ ${ }^{1}$ National Research Technological University "MISIS", Moscow, Russia \\ Correspondence: E. S. Filippov, National Research Technological University "MISIS", Moscow, Russia. E-mail: \\ philippoves@yandex.ru
}

Received: January 15, 2018

Accepted: March 14, 2018

Online Published: May 25, 2018

doi: 10.5539/apr.v10n3p14

URL: https://doi.org/10.5539/apr.v10n3p14

\begin{abstract}
Due to the band structure blurring, all low-temperature characteristics $(p=h k)$ pass to the parameter $\mathrm{R}$ associated with $\lambda_{\mathrm{F}} / 2 \pi$, binding energy, the volume of interatomic voids, the volume increment upon melting, and the packing factor. Application of the parameter R to the analysis of wave characteristics revealed their relationship with the packing factor of the reciprocal lattice (for alkali metals, it is 0.74 , for $\mathrm{Pb}, \mathrm{Al} \ldots$, it is 0.68 ). A correlation is established between the fluctuation cell of heat transfer $\pm \lambda \mathrm{K}$ (where $\lambda=\mathrm{h} / \mathrm{mc}$ and $\mathrm{K}$ is the number of nearest neighbors) and the reciprocal lattice of the atomic-ion space determined by the atom and ion volumes and by the parameter R.
\end{abstract}

Keywords: heat transfer, atomic and ion radii, amorphous structure, cluster, density fluctuation

\section{Introduction and Statement of the Problem}

Blurring of the band structure is uniquely related to the increasing role of electron density fluctuations under the following unchanged characteristics of the condensed state: the Fermi energy and, respectively, the value of $\lambda_{\mathrm{F}} / 2 \pi$, and the binding energy $\mathrm{U}(\mathrm{r})$ and under the pseudopotential approximation of the electron-ion interaction in the coordinate space $r_{a}-r_{i}$ (where $r_{a}$ and $r_{i}$ are the radii of the atom and ion). Consequently, the main assumption in the attempted simulation is the presence of the electron density fluctuations in the interstitial space characterized by the distribution of the electron density probability with respect to $r$ in the atomic-vibrational mode. The main task is to develop a heat transfer model, which is represented as the exchange by fluctuations of high electron density $+\lambda \mathrm{K}$ (emitter) and low electron density $-\lambda \mathrm{K}$ (receiver) in an atomic-coordinate space, which is discrete for the placement in it of cells $\pm \lambda \mathrm{K}$ in the interaction mode: photon + electron $\rightarrow \lambda$ (where $\lambda=\mathrm{h} / \mathrm{mc}$ and $\mathrm{K}$ is the number of the nearest neighbors). We believe that the development such a model adequately reflects the electron-ion interaction at high temperature.

\section{Initial Data and Modeling Results}

The initial data are represented by the main calculated characteristic $\mathrm{R}$ (the half-width of the probability distribution with respect to the coordinate $r$ at the maximum level of the electron density fluctuation), which we find as the average value of the maximum possible values that determine the potential energy at $r_{a}$ and $r_{i} \approx R_{c}$ (minimal and maximum distances from the nucleus):

$$
\mathrm{R}=1 / 2\left(\mathrm{r}_{\mathrm{a}}+\mathrm{R}_{\mathrm{c}}\right)
$$

In accordance with Filippov (2014), we determine the binding energy from the value of R:

$$
\mathrm{U}(\mathrm{r})=\left(\mathrm{e}^{2} / 4 \pi \varepsilon_{0}\right) \mathrm{Z} / \mathrm{K}\left[1 / 2\left(\mathrm{r}_{\mathrm{a}}+\mathrm{R}_{\mathrm{c}}\right)\right]
$$

whereK is the number of nearest neighbors, $\mathrm{Z}$ is the valence, and $\mathrm{R}_{\mathrm{c}}$ is the ion core radius in metals.

On the other hand (the wave case), the value of $\mathrm{R}$ can be justified by the appearance of a standing wave due to the formation of a self-closing orbital (an integer number of wavelengths $2 \pi \mathrm{r}=\mathrm{n} \lambda$ fit in the circle of the radius $\mathrm{r}$ ):

$$
2 \pi \mathrm{r}=2 \pi \mathrm{r}_{\mathrm{i}}+\mathrm{n}(\lambda \mathrm{F} / 2 \pi),
$$

where for $n=1$, we have $r=R_{c}$, for $n=2, r=R$, and where $r_{i}$ is the crystallochemical ion radius.

In addition, the values of $\mathrm{R}$ and $\mathrm{R}_{\mathrm{c}}$, as characteristics of the level of the electron density fluctuation, are related to the atomic coordination, i.e. to the packing factor $k=0.74$ and 0.68. In accordance with Filippov (2017a), we can write: 


$$
\begin{gathered}
\mathrm{k}=\mathrm{V}_{\mathrm{a}} /\left(\mathrm{V}_{\mathrm{a}}+\mathrm{V}_{\mathrm{v}}\right)=\mathrm{r}_{\mathrm{a}}^{3} /\left(\mathrm{r}_{\mathrm{a}}{ }^{3}+\mathrm{R}^{3}\right) ; \\
\mathrm{k}=\mathrm{R}^{3} /\left(\mathrm{R}^{3}+\mathrm{R}_{\mathrm{c}}{ }^{3}\right),
\end{gathered}
$$

where $\mathrm{V}_{\mathrm{a}}$ and $\mathrm{V}_{\mathrm{v}}$ are the volumes of the atom and interatomic voids, respectively.

This implies:

$$
\mathrm{R}^{3} / \mathrm{r}_{\mathrm{a}}{ }^{3}=\mathrm{R}_{\mathrm{c}}{ }^{3} / \mathrm{R}^{3},
$$

and

$$
\begin{aligned}
& \mathrm{R}^{3}=\mathrm{r}_{\mathrm{a}}^{3}\left[\left(\begin{array}{lll}
1 & -\mathrm{k}) / \mathrm{k}] ;
\end{array}\right.\right. \\
& \mathrm{R}_{\mathrm{c}}{ }^{3}=\mathrm{R}^{3}\left[\left(\begin{array}{lll}
1 & -\mathrm{k}) / \mathrm{k}
\end{array}\right]\right. \text {. }
\end{aligned}
$$

It follows from Eq. (4) that the value of $\mathrm{R}^{3}$ corresponds to the volume of interatomic voids, and from Eq. (5), it follows that the volume relations in the interval $R-r_{i}$ correspond to the volume relations in the interval $r_{a}-R$, which means synchronism in theirs changes. These conclusions are confirmed by the analysis of volumetric changes in the liquid phase at the melting point, where $\Delta \mathrm{V}=\mathrm{R}^{3}$ and where $\Delta \mathrm{V}=\mathrm{V}_{1}-\mathrm{V}_{0}\left(\mathrm{~V}_{1}\right.$ is the volume of the liquid phase and $\mathrm{V}_{0}$ is the volume at $0 \mathrm{~K}$ ).

Conclusion: we have reason to take $\mathrm{R}$ as the main parameter of the high-temperature electron-ion interaction (since $\mathrm{R}=\mathrm{f}\left(\lambda_{\mathrm{F}}\right), \mathrm{R}=\mathrm{f}(\mathrm{U}(\mathrm{r})), \mathrm{R}=\mathrm{f}(\mathrm{k})$, and $\left.\mathrm{R}^{3}=\mathrm{V}_{\mathrm{v}}=\Delta \mathrm{V}_{1}\right)$ and apply it to the simulation of the exchange-fluctuation heat transfer. Analysis of the relationship between $R_{c}$ and $r_{i}$ showed that the difference between them corresponds to the minimum possible fluctuation of the electron density in the coordinate linear space among the $\mathrm{K}$ nearest neighbors:

$$
\mathrm{R}_{\mathrm{c}} \quad-\mathrm{r}_{\mathrm{i}}=\mathrm{K} \lambda / \mathrm{Z}
$$

The justification of the value of $K \lambda$ as a thermal fluctuation can be found in the electron-photon interaction, as a result of which the coordinate-atom space has either an excess $+\mathrm{K} \lambda$ or a deficit $-\mathrm{K} \lambda$ in the interaction mode (photon + electron $\rightarrow \lambda$ ) between the photon emitter and their receiver, assuming the number of contacts with the neighboring atoms K (Filippov, 2017a,b) Consequently, in an equilibrium-fibrational mode, the heat fluxes exchanging by the electron density fluctuations $( \pm \mathrm{K} \lambda)$ are equalized as:

$$
\mathrm{R}+\mathrm{K} \lambda=\mathrm{r}_{\mathrm{a}}-\mathrm{K} \lambda / \mathrm{Z} ; \mathrm{R}-\mathrm{K} \lambda=\mathrm{R}_{\mathrm{c}}+\mathrm{K} \lambda / \mathrm{Z}
$$

Here, the number of valence electrons $Z$ is used to take into account the photon absorption limit under the exchange interaction between the fluctuations over $\mathrm{K} \lambda$ in the interval from $r_{\mathrm{a}}$ to $r_{\mathrm{i}}$. Hence, using Eq. (1) and the results of Filippov $(2014,2017 \mathrm{a})$, we can write the following relations:

$\mathrm{R}-\mathrm{R}_{\mathrm{c}}=\mathrm{K} \lambda(1 / \mathrm{Z}+1), \quad \mathrm{R}-\mathrm{r}_{\mathrm{i}}=\mathrm{K} \lambda(2 / \mathrm{Z}+1), \quad \mathrm{r}_{\mathrm{a}}-\mathrm{R}=\mathrm{K} \lambda(1+1 / \mathrm{Z})$, etc.

Thus, in a coordinate-linear space, we can write an expression for the radius of the atom:

where $\mathrm{n}=0,1,2$ for 14 metals.

$$
\mathrm{r}_{\mathrm{a}}=\mathrm{r}_{\mathrm{i}}+2 \mathrm{~K} \lambda(1 / \mathrm{Z}+1)+\mathrm{K} \lambda / \mathrm{Z} \pm \mathrm{n} \lambda,
$$

Consequently, we can assume that the atomic space is divided into ready cells $K \lambda$. Therefore, the transfer of heat energy in this space is modeled as two fluxes relative to $\mathrm{R}$ exchanging by the electron density fluctuations in the $\pm \mathrm{K} \lambda$ mode. This conclusion can be extended to a coordinate-dimensional space considering the transfer of $\mathrm{K} \lambda$ over the volume from $\mathrm{r}_{\mathrm{a}}{ }^{3}$ to $\mathrm{r}_{\mathrm{i}}^{3}$ also with respect to R. Here, the heat transfer process (the exchange model + $\mathrm{K} \lambda \leftrightarrow-\mathrm{K} \lambda$ ) from the emitter to the receiver for the equilibrium-vibrational mode, can be written as: $\Delta \mathrm{V}_{\text {emit }}=$ $\Delta \mathrm{V}_{\text {rec }} \mathrm{Z}$ (where $\mathrm{Z}$ limits the reception of photons), or with respect to the distance from $r_{\mathrm{a}}$ to $\mathrm{r}_{\mathrm{i}}$, as:

$$
\begin{aligned}
\Delta \mathrm{V}_{\text {emit }}=4 \pi\left[1 / 2\left(\mathrm{r}_{\mathrm{a}}+\mathrm{r}_{\mathrm{i}}\right)\right]^{2} \mathrm{~K} \lambda \quad \text { and } \quad \Delta \mathrm{V}_{\text {rec }}=4 \pi\left[1 / 2\left(\mathrm{r}_{\mathrm{a}}+\mathrm{r}_{\mathrm{i}}\right)\right]^{2} \mathrm{~K} \lambda / \mathrm{Z} . \\
\mathrm{V}=\Delta \mathrm{V}_{\text {emit }}+\Delta \mathrm{V}_{\text {red }} / \mathrm{Z}=4 \pi\left[1 / 2\left(\mathrm{r}_{\mathrm{a}}+\mathrm{r}_{\mathrm{i}}\right)\right]^{2} \mathrm{~K} \lambda(1 / \mathrm{Z}+1),
\end{aligned}
$$

where $1 / 2\left(r_{a}+r_{i}\right)$ is the weighted average radius (or the half-width of the probability distribution of the electron density) in the atomic-vibrational mode, at which the maximum level of the probability exchange is assumed to be $\pm K \lambda$. Similar relations can be written for the intervals $\left(R+r_{i}\right)$ and $\left(R+r_{a}\right)$. According to the uncertainty principle, the physical (the wave) volume must correspond to the geometric volume. The search in this direction revealed the following relationships:

$$
\begin{gathered}
\mathrm{V}_{1}=4 \pi\left[1 / 2\left(\mathrm{r}_{\mathrm{a}}+\mathrm{R}\right)\right]^{2} \mathrm{~K} \lambda(1 / \mathrm{Z}+1)=2 \mathrm{r}_{\mathrm{a}}{ }^{3} \\
\mathrm{~V}_{2}=4 \pi\left[1 / 2\left(\mathrm{r}_{\mathrm{a}}+\mathrm{r}_{\mathrm{i}}\right)\right]^{2} \mathrm{~K} \lambda(1 / \mathrm{Z}+1)=\mathrm{r}_{\mathrm{a}}{ }^{3} \mathrm{k}=\mathrm{r}_{\mathrm{a}}{ }^{3}+\mathrm{R}^{3} ; \\
\mathrm{V}_{3}=4 \pi\left[1 / 2\left(\mathrm{r}_{\mathrm{i}}+\mathrm{R}\right)\right]^{2} \mathrm{~K} \lambda(1 / \mathrm{Z}+1)=\mathrm{r}_{\mathrm{a}}{ }^{3},
\end{gathered}
$$


where $R^{3}$ corresponds to the volume of the interatomic voids. Equations (11-13) are satisfied with an accuracy of $\pm 4 \%$ on average.

Analysis of Eqs. (11-13) revealed the relationship between the volumes V1, V2, and V3 and the packing factor k:

$$
\mathrm{V}_{3}=\mathrm{kV}_{2} \mathrm{~V}_{1}=\mathrm{V}_{2} / \mathrm{k} \text {. }
$$

Here, the value of $k$ determined according to the atomic characteristics $\left(r_{a}, r_{i}\right.$, and R) in Eqs. (11-13) for 12 metals was 0.74 and 0.68 in average, as for the fcc and bec packages. However, according to the reciprocal lattice data, i.e., for alkali metals, it was 0.74 , and for $\mathrm{Mg}, \mathrm{Pb}, \mathrm{Al} \ldots$, it was 0.68 .

The following relations between $2 r_{a}^{3}, \quad r_{a}^{3} / k=(1.47-1.35) r_{a}^{3}$, and $1 r_{a}^{3}$ correspond to the value of $k$ of the reciprocal lattice in Eqs. (11-13):

$$
2 / 1.35 \approx 1.47 ; \quad 2 / 1.47 \approx 1.35 ; \quad 1 / 1.35=0.74 ; \quad 1 / 1.47=0.68
$$

Thus, two forms of the atomic-ion volume - the geometric volume and the wave volume are united by the quantity $\mathrm{K} \lambda$.

In accordance with the uncertainty principle, either the charge $(Z)$ must be constant at a variable $r=1 / 2\left(r_{\min }+\right.$ $r_{\max }$ ), or at $r=$ const, the charge should be distributed over a volume defined by $r$ as $Z^{1 / 3}$. This conclusion is realized in our data in the following two relations:

$$
\begin{gathered}
4 \pi \mathrm{R}^{2} \mathrm{~K} \lambda=\left(\mathrm{r}_{\mathrm{a}}{ }^{3}-\mathrm{r}_{\mathrm{i}}^{3}\right) \mathrm{Z}^{1 / 3} ; \\
4 \pi \mathrm{R}_{\mathrm{c}}{ }^{2} \mathrm{~K} \lambda=\mathrm{R}^{3} \mathrm{Z}^{1 / 3},
\end{gathered}
$$

where $r_{i} \rightarrow R_{c}$, since $R_{c}=r_{i}+K \lambda / Z$ according to Eq.(3).

The accuracy of these relationships is $\pm 5 \%$ on average.

In general, there is reason to conclude that the model for the transfer of thermal energy in space from ri to ra can be represented as two fluxes relative to R exchanging by the fluctuations of increased $(+K \lambda)$ and lower $(-K \lambda)$ electron density.

\section{Consequences From the Model of Heat Transfer}

\subsection{Features of the heat transfer for $\mathrm{Cu}, \mathrm{Ag}$, and $\mathrm{Au}$.}

The values of $\mathrm{r}_{\mathrm{a}}-\mathrm{r}_{\mathrm{i}}=0.32 \AA$ for $\mathrm{Cu}$ and $0.28 \AA$ for $\mathrm{Ag}$ coincide with the value of $\mathrm{K} \lambda=$ $0.29 \AA$ within $\pm \lambda$. For Au, $r_{a} \quad-r_{i}=0.045 \AA$ corresponds to $2 \lambda=0.048 \AA$ also within $\pm \lambda$. These data correlate with high level of heat transfer in these metals.

\subsection{Transition Metals.}

Here, there is a limit in determining the values of $\mathrm{R}$ and $\mathrm{R}_{\mathrm{c}}$, since s-d and d-bands of the electronic system affect $\mathrm{k}_{\mathrm{F}}$. For example, for $\mathrm{Ni}, \mathrm{k}_{\mathrm{F}}=0.55$ a.u. (s-d band) and $\mathrm{k}_{\mathrm{F}}=0.81$ a.u. (d-band), i.e., $\mathrm{k}_{\mathrm{F}} \neq$ const. However, it is possible to assume that $R_{c} \rightarrow r_{i}$, which allows us to define $R$ as $1 / 2\left(r_{a}+r_{i}\right)$ and also the equality of fluctuation fluxes with the excess $(+\mathrm{K} \lambda)$ and the deficit $(-\mathrm{K} \lambda)$ as:

$$
\mathrm{R}-\mathrm{r}_{\mathrm{i}}=\mathrm{nk} \lambda \pm \lambda \text { and } \mathrm{r}_{\mathrm{a}}-\mathrm{R}=\mathrm{nK} \lambda \text {, }
$$

where $\mathrm{n}=1,2$.

For example, for $\mathrm{Ni}(\AA \hat{\AA} /$ atom $): \quad \mathrm{R}=(1.26+0.72) / 2=0.99$;

$$
\begin{gathered}
\mathrm{R}-\mathrm{r}_{\mathrm{i}}=0.99-0.72=0.27 ; \\
\mathrm{K} \lambda=12.0 .024=0.29 .
\end{gathered}
$$

For example, for Y:

$$
\text { where } 0.27 \approx 0.29 \text { at } \mathrm{n}=1 \text {. }
$$

$$
\begin{gathered}
\mathrm{R}=(1.64+0.88) / 2=1.26 ; \\
\mathrm{R}-\mathrm{r}_{\mathrm{i}}=1.26-0.88=0.38 ; \\
2 \mathrm{~K} \lambda=2.8 . \quad 0.024=0.38, \quad \text { where } \mathrm{n}=2 .
\end{gathered}
$$

Equation (17) is satisfied with an accuracy of $\pm 4 \%$ for $\mathrm{Ni}, \mathrm{Cu}, \mathrm{Mo}, \mathrm{Nb}, \mathrm{Y}, \mathrm{Ti} \ldots$ similar to Eq. (8) for the nontransition metals. 


\subsection{Amorphous State}

We consider the quantity $\left(r_{a}-r_{i}\right) / K \quad$ as a dimensional criterion for the formation of an amorphous state. The main assumption is the freezing of atomic exchange between the cluster, which has $\mathrm{K}=12$ or 8 , and a chaotic packing (or an SP-statistical packing having $\mathrm{K}=6.5=1 / 12(1+2+3+\ldots+12)$, where all coordinations are equally probable Filippov, 2014, 2017a,b). This state can be defined as frozen crystallization, where not any crystallization can be developed: neither crystallization from SP, nor that from clusters under ideal conditions of heat energy removal from clusters with ordered packing and chaotic one (SP) that can be created at a distance of $\left(r_{a}-r_{i}\right)$, where the $K \lambda$ cells can fit an integer $n$ times:

for clusters: $\quad r_{a}-r_{i}=n_{1} K \lambda, \quad$ for $S P: \quad \sigma / 2-r_{i}=n_{2} K_{S P} \lambda$,

where

$$
\mathrm{K}=12 \text { or } 8 \text { for a cluster and } \mathrm{K}_{\mathrm{SP}}=6.5 \text { and } \mathrm{n}=1,2,3, \sigma / 2=0,867 \mathrm{r}_{\mathrm{a}} \text { (Filippov, 2014, 2017a,b). }
$$

However, $n_{1} \neq n_{2}$. The ideal condition for the heat removal is the equality of the cells $n K \lambda$ of the cluster and SP. This equality of cells can be created with the help of composite fractions $\mathrm{x}, \mathrm{y}, \mathrm{z}$ in a combination of two or three metals, i.e., by fitting to the total integer $n$. For example, for a pair of metals $A_{x} B_{y}$, we have

$$
\begin{aligned}
& \text { Cluster A Cluster BSP }(\mathrm{A} \text { or } \mathrm{B}) \\
& \mathrm{x}\left[\left(\mathrm{r}_{\mathrm{a}}-\mathrm{r}_{\mathrm{i}}\right) / \lambda \mathrm{K}_{12.8}\right]_{\mathrm{A}}+\mathrm{y}\left[\left(\mathrm{r}_{\mathrm{a}}-\mathrm{r}_{\mathrm{i}}\right) / \lambda \mathrm{K}_{12.8}\right]_{\mathrm{B}}=(\mathrm{x}, \mathrm{y})\left[\left(\begin{array}{lll}
\mathrm{r}_{\mathrm{a}} & \left.\left.-\mathrm{r}_{\mathrm{i}}\right) / \lambda \mathrm{K}_{\mathrm{SP}}\right]_{\mathrm{A}, \mathrm{B}}
\end{array}\right.\right.
\end{aligned}
$$

$\mathrm{n}_{\mathrm{A}} \mathrm{n}_{\mathrm{B}} \mathrm{n}_{\mathrm{SP}}$

$$
\mathrm{n}_{\mathrm{A}}+\mathrm{n}_{\mathrm{B}}=\mathrm{n}_{\mathrm{Cy}}=\mathrm{n}(\text { an integer: } 1,2,3)
$$

The adequacy of Eq. (18) can be shown for the specific combinations of metals that lead to the amorphous phase after annealing using experimental data taken from a review article by Jonson (1986), for example, for $\mathrm{Ni}_{0.31} \mathrm{Y}_{0.69}$ :

$$
\begin{array}{rlrrr}
\left(0.69 \Delta \mathrm{r}_{\mathrm{Y}}+\right. & \left.0.31 \Delta \mathrm{r}_{\mathrm{Ni}}\right) / \lambda & = & {\left[\left(0.69 \Delta \mathrm{r}_{\mathrm{Y}}\right)_{\mathrm{SP}}\right] / \lambda} \\
\Sigma \mathrm{n}=3.2 & \mathrm{n}_{\mathrm{SP}}=3.1 & \mathrm{n} \approx 3.0 .
\end{array}
$$

where $\Delta r_{\mathrm{Y}}=\left(\mathrm{r}_{\mathrm{a}}-\mathrm{r}_{\mathrm{i}}\right) / 8 ; \quad \Delta \mathrm{r}_{\mathrm{Ni}}=\left(\mathrm{r}_{\mathrm{a}}-\mathrm{r}_{\mathrm{i}}\right) / 12 ; \quad \Delta \mathrm{r}_{\mathrm{SP}}=\left(\mathrm{r}_{\mathrm{a}}-\mathrm{r}_{\mathrm{i}}\right)_{\mathrm{Y}} / 6.5$.

Similarly, a number of other combinations of metals that lead to an amorphous phase after diffusion annealing or bombardment with $\mathrm{Kr}$ ions have been analyzed: $\mathrm{Ti}_{31} \mathrm{Nb}_{22} \mathrm{Cu}_{47}, \mathrm{Al}_{55} \mathrm{Nb}_{45}, \mathrm{Ni}_{40} \mathrm{Nb}_{60}$, and others. All of them are satisfied by Eq. (18) to within $\pm 4 \%$ for $n=1,2$, or 3. (the value of $n=3$ also follows from Eq. (9) for $Z$ from 2 to 5). In conclusion, it should be noted a distinct parallel between the data for precious metals and the data following from Eq. (18).

\section{References}

Filippov, E. S. (2014). High-Temperature Structure Formation in Metals. Russian Physics Journal, 56(12), 1333 1338.

Filippov, E. S. (2017). Model of High Temperature Heat Transfer in Metals. Global Journal of Science Frontier Research, 17(4).

Filippov, E. S. (2017b). Model of Melting and Heat Transfer in Metals. Applied Physics Research, 9(2), 1.

Johnson, W. L. (1986). Thermodynamic and kinetic aspects of the crystal to glass transformation in metallic materials. Progress in Materials Science, 30(2), 81-134.

\section{Copyrights}

Copyright for this article is retained by the author(s), with first publication rights granted to the journal.

This is an open-access article distributed under the terms and conditions of the Creative Commons Attribution license (http://creativecommons.org/licenses/by/4.0/). 